\title{
Effect of Phytase Transgenic Corn Supplemented in Feed Diets on the Utilization of Calcium and Phosphorus in Bama Boars
}

\begin{abstract}
Liqin $\mathrm{LH}^{\# \#}$, J inghuan $\mathrm{W}^{2 \#}$, Deqian $\mathbf{M}^{2}$, Min $\mathbf{L i}^{2}$, Xiaoguang $Y^{2}$ and Lichen $Y^{2 *}$

${ }^{1}$ Shanxi Center for Disease Control and Prevention, China ${ }^{2}$ Key Laboratory of Trace Element Nutrition of National Health Commission of China, National Institute for Nutrition and Health, Chinese Center for Disease Control and Prevention, China

"Contributed Equally to this Work

*Corresponding author: Lichen Y, Key Laboratory of Trace Element Nutrition of National Health Commission of China, National Institute for Nutrition and Health, Chinese Center for Disease Control and Prevention, 29 Nanwei Road, Xicheng District, Beijing, China
\end{abstract}

Received: August 25, 2021; Accepted: September 28, 2021; Published: October 05, 2021

\begin{abstract}
The study aimed to evaluate the nutritional composition and the efficacy of phytase transgenic corn. Ten-month old castrated Bama boars and replicated a $6 \times 6$ Latin square design were used to evaluate the effect of phytase on utilization of calcium of phosphorus. Six-dietary treatments included: Phosphorus adequate control diet (PC), PTC0 (low-phosphorus diet), PTC500 (lowphosphorus diet with 500 FTU phytase/kg in PTC), PTC1000 (low-phosphorus diet with 1000 FTU phytase/kg in PTC), PTC5000 (low-phosphorus diet with 5000 FTU phytase/kg in PTC), microbe500 (low-phosphorus diet with 500 FTU phytase $/ \mathrm{kg}$ from Aspergillus Niger). Contents of the proximate components, minerals, vitamins and amino acid of PTC did not differ from CC. The PTC has lower concentrations of phytate phosphorus than $\mathrm{CC}$, the apparent digestibility of calcium and phosphorus of the PTCO group is lower $(p<0.05)$. No obvious dose-dependent relationship about the apparent digestibility of calcium and phosphorus showed among PTC500, PTC1000 and PTC5000. Therefore, the nutritional compositions of PTC had substantial equivalence to that of control corn except for phytate phosphorus concentrations, the PTC addition can improve the apparent digestibility of phosphorus and calcium and reduce the excrement of inorganic phosphorus, PTC might be an economically efficient way to decrease environment pollutions.
\end{abstract}

Keywords: Phytase transgenic corn; Nutritional composition; Calcium; Phosphorus; Utilization

\section{Abbreviations}

PTC: Phytase Transgenic Corn; CC: Conventional Corn; PC: Phosphorus Adequate Control; AD: Apparent Digestibility; SD: Standard Deviation; OECD: Organization for Economic Cooperation and Development; WHO: World Health Organization; GMO: Genetically Modified Organism

\section{Introduction}

Phosphorus and calcium are two of the essential mineral elements in animal growth, which play important role in bone development and energy metabolism [1]. Phytate is the major storage form of phosphorus in many plant feed ingredients [2-4]. However, phytatephosphorus is poorly utilized by nonruminant animals such as pigs and poultry, and thereby inorganic phosphorus needs to be added to the feed to meet their phosphorus requirements [5]. The unavailable phytate-phosphorus will be excreted and consequently cause environmental pollution problems. In addition, phytate in plants can chelate divalent metal ions such as calcium and iron in feeding process, and result a poor utilization of these elements [6].

Some research reported that supplementation of exogenous microbial phytase in feed might be one of the most effective methods to enhance the utilization of phosphorus and reduce its excretion in nonruminant animals [7,8]. But this way is often hard to be applied because of the high cost and inconvenience of production in developing countries [9]. With the development of biotechnology, foreign phytase gene was efficiently expressed in maize, which is extremely promising in terms of environmental health $[10,11]$. However, public concerns have been raised in regard to the nutritional value, the usage and their potential effects of genetically modified crops on animal and human health [12].

Up to date, several studies have been conducted to compare the feed safety values of PTC with CC in poultry, such as laying hens and broiler $[13,14]$. However, the nutritional values and the utilization of calcium and phosphorus have been observed inadequately between PTC and CC when pigs consuming diets formulated with these corns. Therefore, the aim of this study was: 1) To assess whether the nutritional composition (proximate components, mineral, vitamin energy and amino acids) of PTC were equivalent to CC; and 2) To evaluate the efficacy of corn-based phytase as a dietary supplement for poultry on the utilization of calcium of phosphorus.

\section{Materials and Methods}

\section{Materials}

Genetically modified PTC TPY002 and its CC were provided by Beijing Origin Agritech Limited, and the phytase from Aspergillus Niger was purchased from Beijing Challenge Group. The whole grain from PTC and CC were ground to a $0.5-\mathrm{mm}$ mesh screen before analysis or inclusion into the diets.
Ann Agric Crop Sci - Volume 6 Issue 6 - 2021

ISSN: 2573-3583 | www.austinpublishinggroup.com

Liqin et al. (C) All rights are reserved
Citation: Liqin LH, Jinghuan W, Deqian M, Li M, Xiaoguang Y and Lichen Y. Effect of Phytase Transgenic Corn Supplemented in Feed Diets on the Utilization of Calcium and Phosphorus in Bama Boars. Ann Agric Crop Sci. 2021; 6(6): 1095 


\section{Composition analysis}

The concentrations of proximate components, mineral, vitamin and amino acids of PTC and CC were analyzed according to standard methods for protein (GB 87 5009.5-2010, China, 2010), total fat (GB/T 5009.6-2003), carbohydrate (GB/Z 88 21922-2008), fiber (GB/T 5009.88-2008), calcium (GB/T 5009.92-2003), copper 89 (GB/T 5009.13-2003), iron, magnesium and manganese (GB/T 5009.902003), 90 potassium (GB/T 5009.92-2003), zinc (GB/T 5009.142003), selenium (GB 5009.93-2010), phosphorus (GB/T 5009.872003), sodium (GB/T 5009.91-2003), thiamine (GB/T 5009.84-2003), riboflavin (GB/T 5009.85-2003), folic acid (GB/T 5009.211-2008), niacin (GB/T 5009.89-2003), free biotin (GB 5413.19-2010), Amino acid content (GB/T 5009.124-2003). Each nutrient was detected triple.

\section{Determination of phytase activity}

Phytase activity in corns was determined according to the standard method (GB/T 18634-2009, China, 2009). One phytase activity unit (FTU) is defined as the quantity of enzyme that releases $1 \mu \mathrm{mol}$ of inorganic phosphorus per min from $5.5 \mathrm{mmol} / \mathrm{L}$ sodium phytate at $\mathrm{pH} 5.5$ at $37^{\circ} \mathrm{C}$.

\section{Experimental scheme and design}

Animals: Ten-month old castrated Bama boars were bought from Beijing Tonghe Shengtai Institute of Comparative Medicine (License: SCXK (Beijing), 2015-0004). They were individually housed in stainless steel cages with the laboratory temperature $20^{\circ} \mathrm{C}-25^{\circ} \mathrm{C}$ and humidity $40-70 \%$. All pigs were surgically fitted with post-valve T-intestinal cannulas after 36-hour fasting control. Six swines, which were well recovered from the surgery and with good appetite, were selected. The protocol was approved by the Experimental Animal Welfare and Ethics Committee of National Institute for Nutrition and Health, Chinese Center for Diseases Control and Prevention.

Dietary treatments: According to the references [15,16], sixdietary treatment in the present study included: (1) Phosphorus adequate control diet (PC): daily feed with adequate phosphorus to meet its requirements of the pigs; (2) PTC0: low-phosphorus diet in which phosphorus content was reduced by $1 / 3$ on the basis of PC diet but the ratio of calcium to phosphorus was unchanged; (3) PTC500: low-phosphorus diet added PTC with 1000 FTU phytase/kg; (4) PTC1000: low-phosphorus diet added PTC with 1000 FTU phytase/ kg; (5) PTC5000: low-phosphorus diet added PTC with 5000 FTU phytase/kg; (6)microbe 500: low-phosphorus diet added 500 FTU phytase/kg from Aspergillus Niger.

Feed formula was prepared to meet the nutritional requirements of this small type pigs [17]. Soybean meal and vegetable oil was nongenetically modified. The detailed formula was shown in Table 1.

Experimental procedure: A replicated $6 \times 6$ Latin square design was applied for PTC with different level of phytase activity and CC comparison. Each diet was supplied for 6 days. All swines were fed twice per day with equal amounts of each meal at 12-hour intervals (from 8:00 to 20:00). On the seventh and eighth day, faeces were collected by self-designed honeycomb ducts with once per hour from 8:00 to 20:00 and frozen immediately at $-20^{\circ} \mathrm{C}$. After two days faeces collection, pigs were given a new diet. All the faeces were freeze-dried, ground through a $0.250-\mathrm{mm}$ mesh screen and then determined the concentration of calcium, phosphorus and chromium.

\section{Analytical methods}

The digestibility of calcium and phosphorus was calculated by Apparent Digestibility (AD). Parameters of digestibility were calculated using the following equation $[18,19]$ :

$\mathrm{AD} \%=100-\left(\mathrm{Cr}_{\text {feed }} / \mathrm{Cr}_{\text {feces }}\right) *\left(\mathrm{~A}_{\text {feces }} / \mathrm{A}_{\text {feed }}\right) * 100$

Where $C r_{\text {feed }}$ is the content of chromiumin diet $(\mathrm{mg} / \mathrm{kg}), C r_{\text {feces }}$ is the content of chromiumin fecest $(\mathrm{mg} / \mathrm{kg}), A_{\text {feces }}$ is the content of nutrients in digesta $(\mathrm{g} / \mathrm{kg})$, and $A_{\text {feed }}$ is the content of nutrients in diet $(\mathrm{g} / \mathrm{kg})$.

The data were analyzed with the SPSS software (version 19.0; SPSS, Inc., Chicago, IL, USA). Descriptive data were presented as mean \pm standard deviation (SD). Reference values from Organization for Economic Co-operation and Development (OECD) was used to compare the difference in nutrients level between PTC and CC. Differences among comparisons of digestibility values obtained from pigs were analyzed by the variance analysis. A two-tailed $\mathrm{p}$-value $<0.05$ was considered statistically significant.

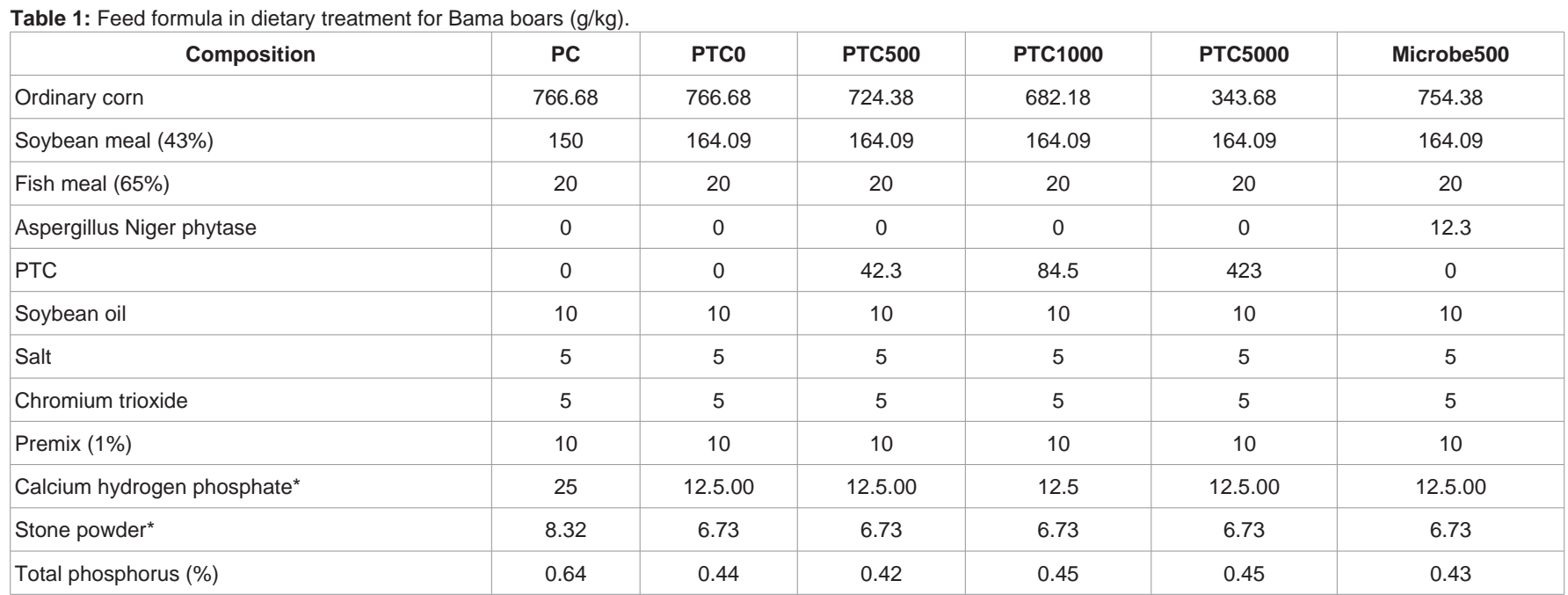

Note: Calcium hydrogen phosphate including calcium $20.35 \%$, phosphorus $17.62 \%$, stone powder including calcium $35 \%$. 
Table 2: Comparison of nutrients' content between PTC and CC.

\begin{tabular}{|c|c|c|c|}
\hline Nutrients & PTC & $\mathrm{CC}$ & Reference values* \\
\hline \multicolumn{4}{|l|}{ Proximate components } \\
\hline Protein (g/100g) & $7.93 \pm 0.83$ & $7.29 \pm 0.16$ & $6.00-12.70$ \\
\hline Total fat $(\mathrm{g} / 100 \mathrm{~g})$ & $4.35 \pm 0.07$ & $4.40 \pm 0.14$ & 3.1-5.8 \\
\hline Carbohydrate (g/100g) & $70.22 \pm 8.31$ & $64.36 \pm 1.17$ & - \\
\hline Fiber (g/100g) & $11.53 \pm 2.22$ & $10.76 \pm 1.32$ & $8.30-11.90$ \\
\hline \multicolumn{4}{|l|}{ Minerals } \\
\hline phosphorus (g/100g) & $0.26 \pm 0.00$ & $0.22 \pm 0.01$ & $0.23-0.72$ \\
\hline potassium(mg/100g) & $190.21 \pm 121.03$ & $195.99 \pm 114.74$ & $320-720$ \\
\hline magnesium (mg/100g) & $115.60 \pm 8.57$ & $96.71 \pm 0.25$ & $82-1000$ \\
\hline calcium (mg/100g) & $5.04 \pm 0.28$ & $6.43 \pm 1.65$ & $3-100$ \\
\hline iron (mg/100g) & $2.54 \pm 0.05$ & $2.05 \pm 0.45$ & $0.1-10$ \\
\hline zinc (mg/100g) & $18.50 \pm 0.71$ & $23.50 \pm 4.95$ & $1.2-3.0$ \\
\hline sodium (mg/100g) & $0.83 \pm 0.49$ & $0.64 \pm 0.23$ & $0-150$ \\
\hline \multicolumn{4}{|l|}{ Vitamins } \\
\hline Vitamin A ( $\mu \mathrm{g} / 100 \mathrm{~g})$ & $7.67 \pm 0.01$ & $5.74 \pm 0.01$ & - \\
\hline Vitamin E (mg/100g) & $4.41 \pm 1.87$ & $4.33 \pm 0.30$ & - \\
\hline Thiamine (mg/100g) & $0.17 \pm 0.08$ & $0.17 \pm 0.05$ & $0.23-0.86$ \\
\hline Riboflavin (mg/100g) & $0.03 \pm 0.00$ & $0.03 \pm 0.01$ & $0.025-0.56$ \\
\hline Vitamin $B_{6}(\mathrm{mg} / 100 \mathrm{~g})$ & $0.32 \pm 0.06$ & $0.36 \pm 0.01$ & - \\
\hline Vitamin $B_{12}(\mu \mathrm{g} / 100 \mathrm{~g})$ & $0.27 \pm 0.07$ & $0.30 \pm 0.06$ & - \\
\hline \multicolumn{4}{|l|}{ Phytate } \\
\hline phytate phosphorus (g/100g) & $0.02 \pm 0.01$ & $0.12 \pm 0.01$ & - \\
\hline
\end{tabular}

Note: *Data from OECD (2002); - indicated data not given.

\section{Results}

\section{The content of nutritional composition in PTC and CC}

Analyzed nutrient contents of the corns were presented in Table 2. Contents of the proximate components, minerals and vitamins of PTC did not differ greatly from CC. All vales of both corns were in the range of reference values recommended by OECD. The content of phytate phosphorus, the ratio of phosphorus to phytate phosphorus in PTC was obviously lower than that in CC (7.7\% and 54.5\%).

The content of amino acids in PTC and CC were presented in Table 3. Although there was a little difference between the two corns, all vales were in the range of reference values recommended by OECD.

\section{The phytase activity of PTC}

The genetical modified phytase maize was cultivated by the gene gun mediated transformation with Aspergillus-Niger phyA2 gene. The phytase in the PTC and Aspergillus Niger were both acid phytase. The phytase activity was $11832 \mathrm{FTU} / \mathrm{kg}$ for PTC, and 40691FTU/kg for Aspergillus Niger.

\section{The apparent digestibility of calcium and phosphorus}

All pigs were normal in diet intake and water drinking, and were in good condition throughout the whole experiment. The apparent digestibility of calcium and phosphorus was presented in Table 4.
Table 3: Comparison of amino acids' content between PTC and CC (g/100g).

\begin{tabular}{|c|c|c|c|}
\hline Nutrients & PTC & $\mathrm{CC}$ & Reference values* \\
\hline Aspartic Acid & 0.55 & 0.48 & $0.48-0.85$ \\
\hline Threonine & 0.24 & 0.23 & $0.27-0.58$ \\
\hline Serine & 0.38 & 0.33 & $0.35-0.91$ \\
\hline Glutamic & 1.56 & 1.44 & $1.25-2.58$ \\
\hline Glycine & 0.23 & 0.22 & $0.26-0.49$ \\
\hline Alanine & 0.67 & 0.6 & $0.56-1.04$ \\
\hline Valine & 0.33 & 0.32 & $0.21-0.85$ \\
\hline Methionine & 0.12 & 0.13 & $0.10-0.46$ \\
\hline Isoleucine & 0.17 & 0.15 & $0.22-0.50$ \\
\hline Leucine & 1 & 0.93 & $0.79-2.41$ \\
\hline Tyrosine & 0.19 & 0.17 & $0.12-0.79$ \\
\hline Phenylalanine & 0.37 & 0.34 & $0.32-0.64$ \\
\hline Lysine & 0.24 & 0.22 & $0.05-0.55$ \\
\hline Hlstidine & 0.19 & 0.2 & $0.15-0.38$ \\
\hline Argnine & 0.33 & 0.28 & $0.22-0.64$ \\
\hline Proline & 0.55 & 0.59 & $0.63-1.36$ \\
\hline Tryptophane & 0.06 & 0.06 & - \\
\hline Cystine & 0.1 & 0.1 & - \\
\hline
\end{tabular}

Note: *Data from OECD (2002); - indicated data not given. 


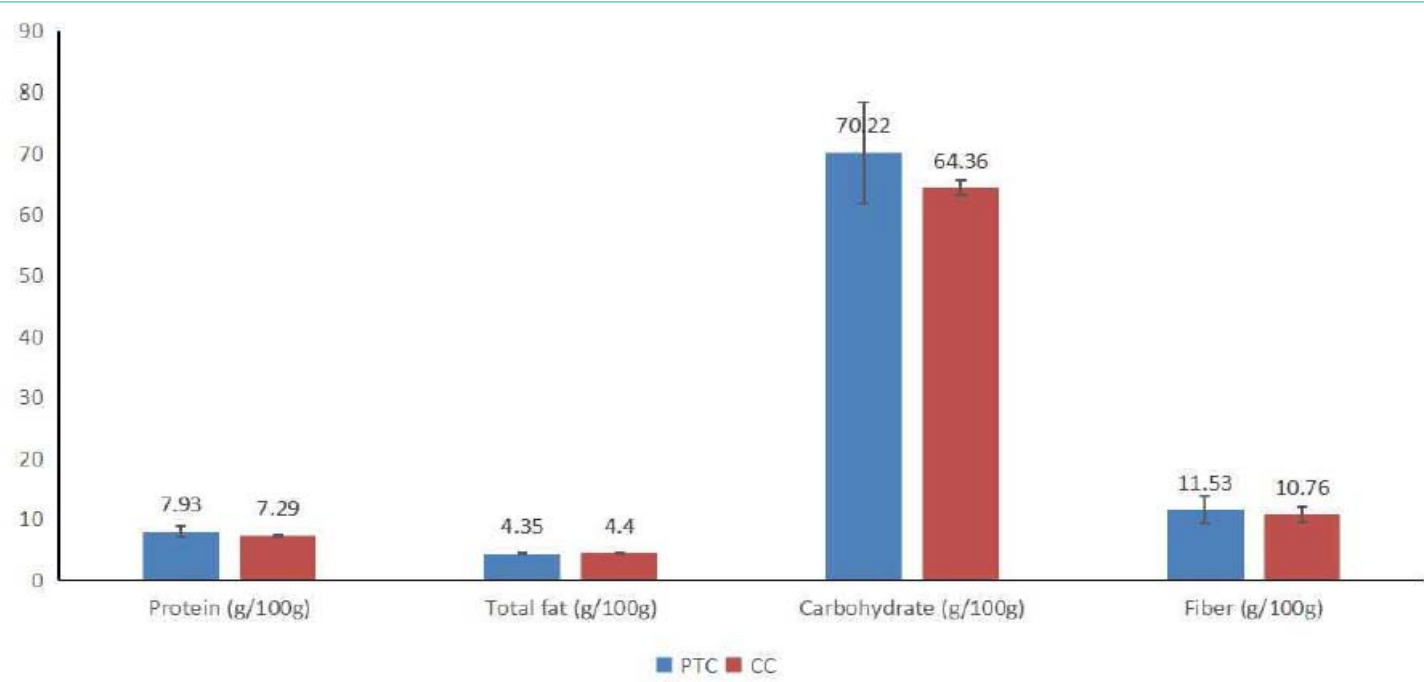

Figure 1: Comparison of nutrients content between PTC and CC

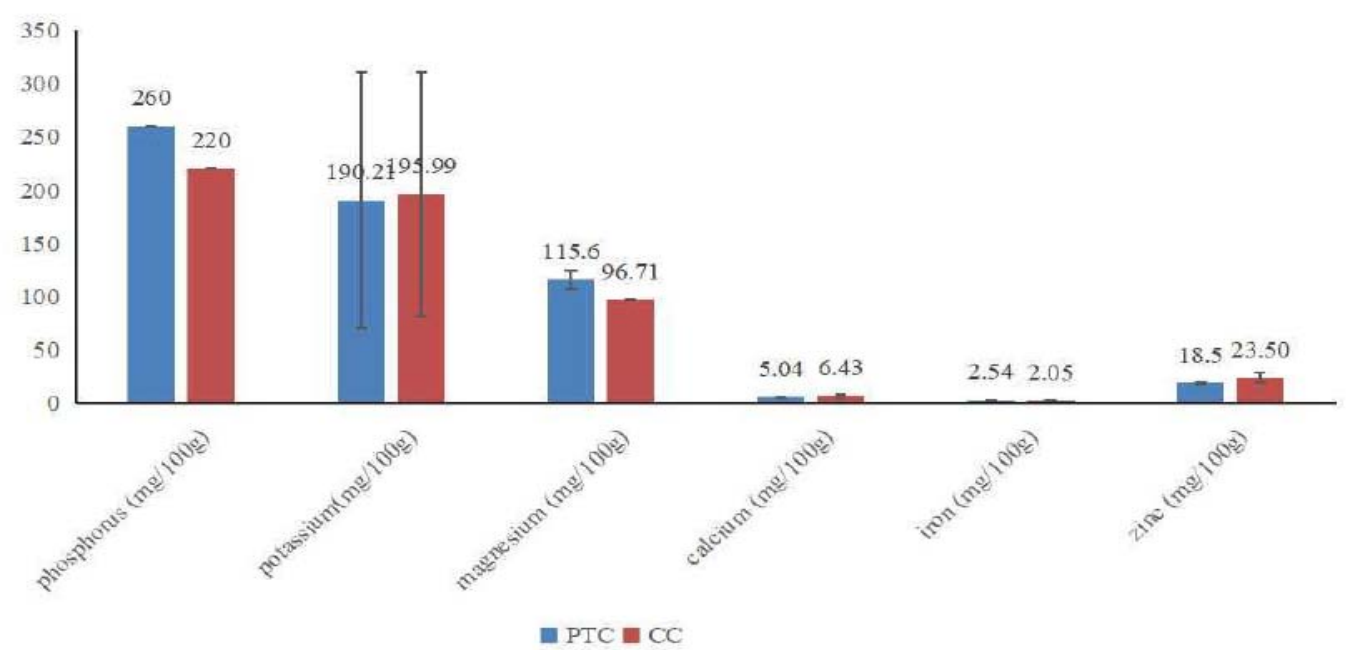

Figure 2: Comparison of minerals content between PTC and CC.

Compared with the PTC0 group, the apparent digestibility of calcium and phosphorus were significantly higher in groups of CC, PTC500, PTC1000, PTC5000 and microbe500 (calcium: 59.31\%; 47.87; 61.15\%; $61.88 \%$; 60.27\%; 60.57\%; phosphorus: 42.96\%; 30.72\%; 46.13\%; $47.44 \% ; 49.02 ; 45.49$ all $\mathrm{p}<0.05)$. The apparent digestibility of calcium and phosphorus in PTC500, PTC1000, PTC5000 group was similar as groups of microbe500 (all p>0.05). However, no obviously dosedependent manner between the apparent digestibility of calcium and phosphorus and different level of phytase activity was showed among groups of PTC500, PTC1000 and PTC5000.

The result displayed that the addition of phytase corn with $500 \mathrm{FTU} / \mathrm{kg}$ and above enzyme activity could reduce the amount of calcium hydrogen phosphate by $1 / 3$ when preparing feed for pigs. In addition, phytase activity in PTC was effective as that from Aspergillus Niger.

\section{Discussion}

The PTC is an innovative way of adding exogenous microbial phytase to corns for monogastric animals feeding. According to the guidance of World Health Organization (WHO) workshop, nutritional components analysis between PTC and its control production is one of important aspects for safety evaluation of foods or food components from plants derived by modern biotechnology [20]. To date, the principle of "substantial equivalence" has been used internationally for safety assessing of Genetically Modified Organism (GMO). There may be some change in key nutrients' content between GMO and their control production, which could be related to natural variation, meteorological conditions, soil conditions, etc. Therefore, it can be regarded as there is no difference between the GMO and control production as long as the values were in the range of variation [21].

Several studies showed that microbial phytase supplementation can significantly improve phosphorus utilization in nonruminant animal diets [22,23] However, it cost highly and could not use extensively in the feed production. The PTC derived by exogenous microbial phytase and supplemented into diet, could be an 


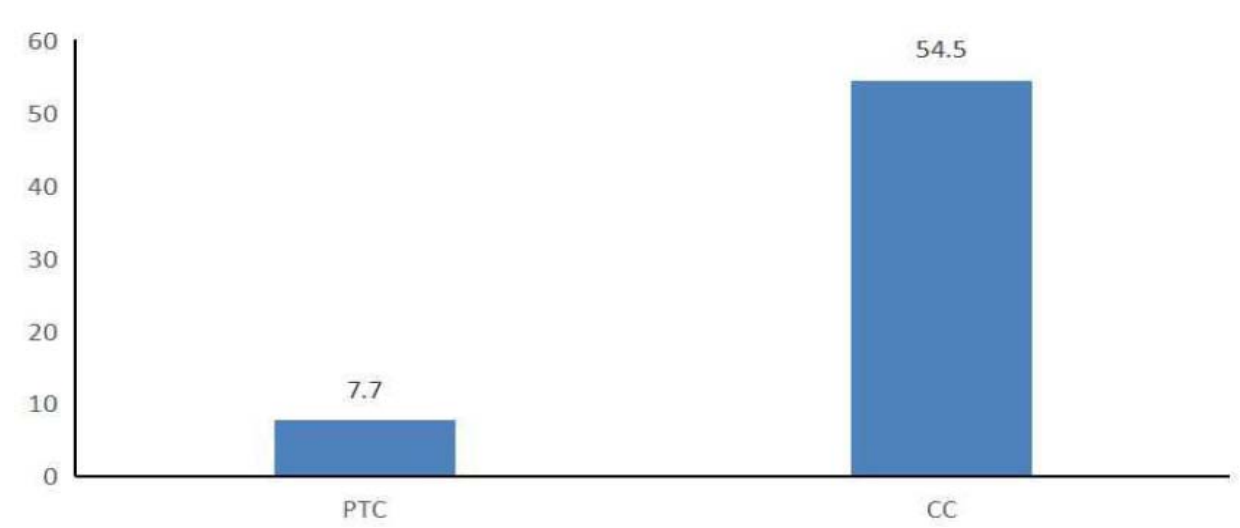

Figure 3: Ratio of phytate phosphorus to phosphorus (\%).

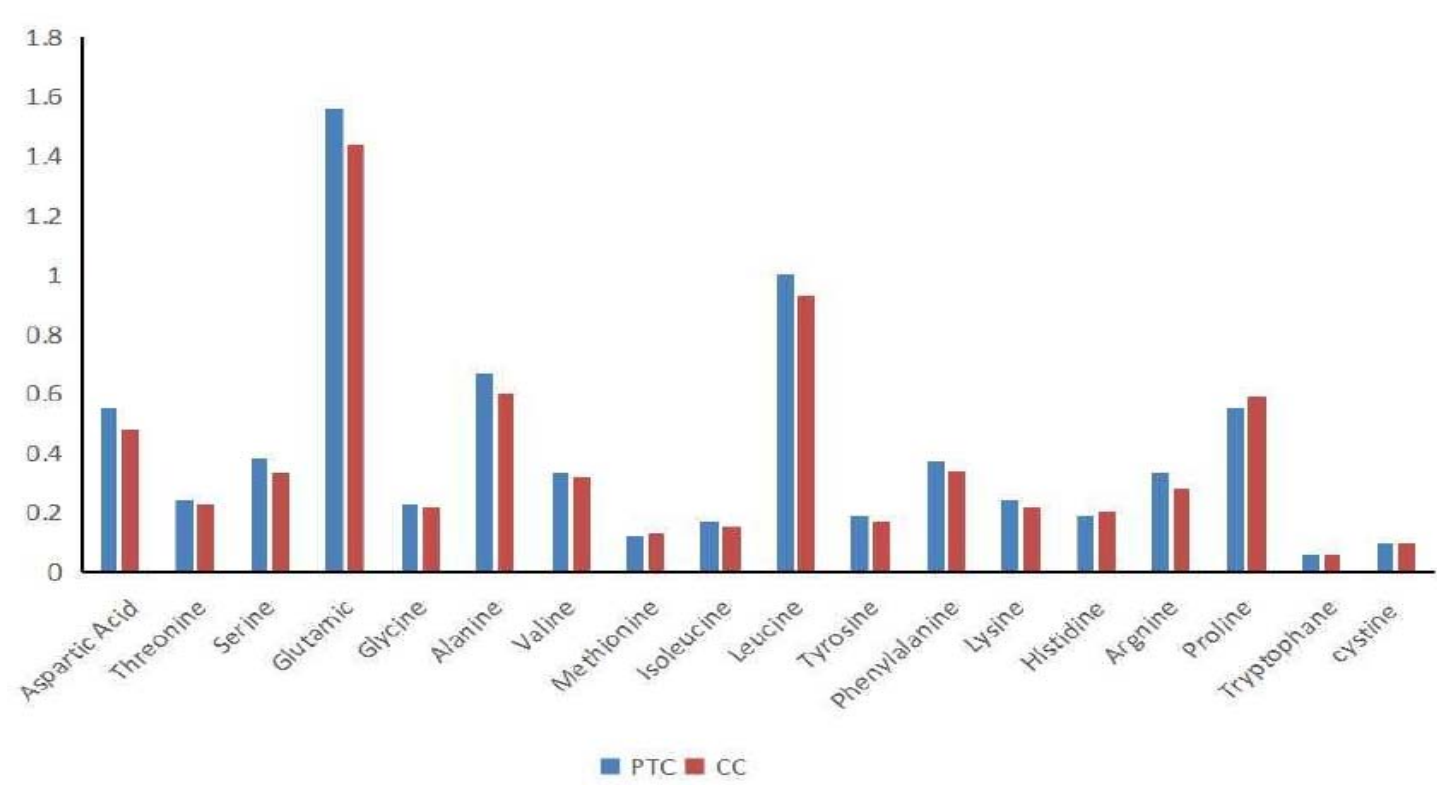

Figure 4: Comparison of amino acids content between PTC and CC (g/100g).

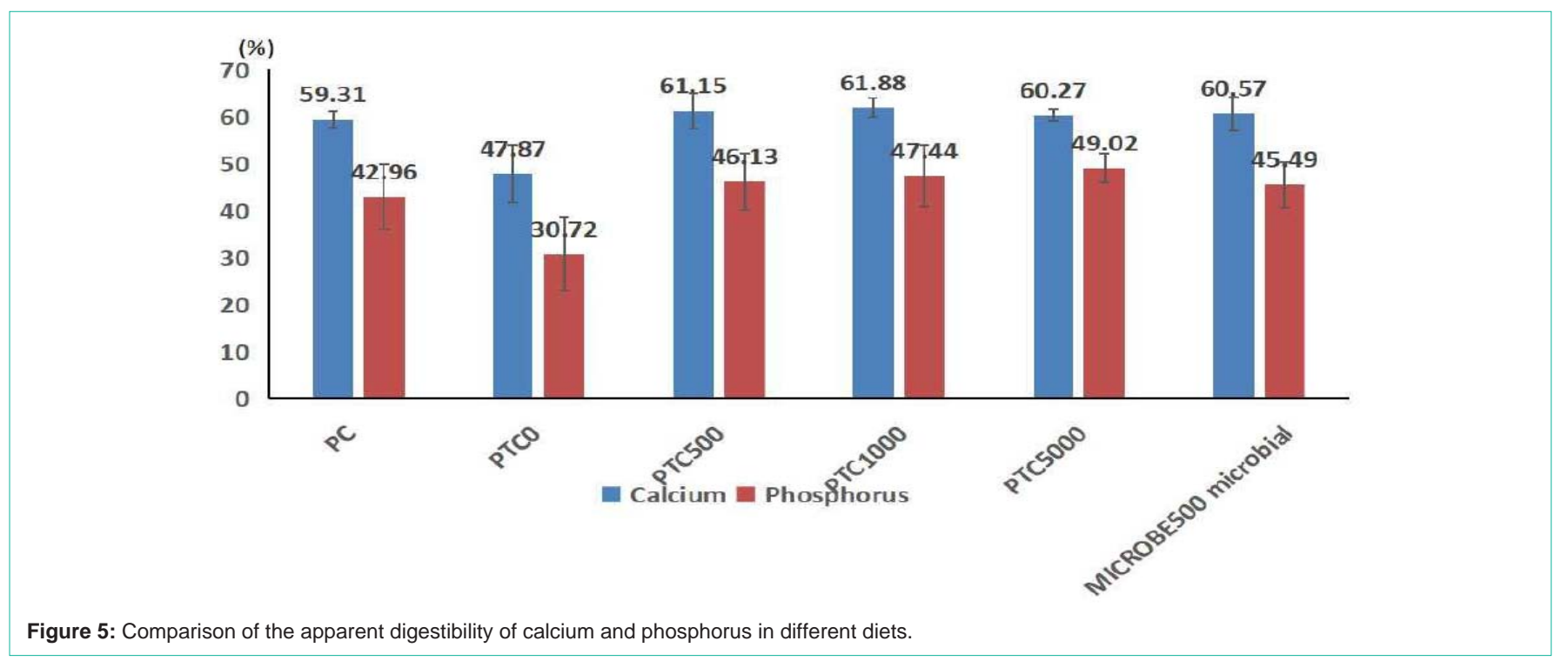


Table 4: Comparison of the apparent digestibility of calcium and phosphorus in different diets (\%).

\begin{tabular}{|l|c|c|c|c|c|c|}
\hline \multicolumn{1}{|c|}{ Nutrients } & PC & PTC0 & PTC500 & PTC1000 & PTC5000 & MICROBE500 microbial \\
\hline Calcium & $59.31 \pm 1.70^{\mathrm{a}}$ & $47.87 \pm 6.12^{\mathrm{b}}$ & $61.15 \pm 3.72^{\mathrm{a}}$ & $61.88 \pm 1.97^{\mathrm{a}}$ & $60.27 \pm 1.24^{\mathrm{a}}$ & $60.57 \pm 3.67^{\mathrm{a}}$ \\
\hline Phosphorus & $42.96 \pm 6.93^{\mathrm{a}}$ & $30.72 \pm 7.88^{\mathrm{b}}$ & $46.13 \pm 5.97^{\mathrm{a}}$ & $47.44 \pm 6.58^{\mathrm{a}}$ & $49.02 \pm 3.09^{\mathrm{a}}$ & $45.49 \pm 4.81^{\mathrm{a}}$ \\
\hline
\end{tabular}

Note: Groups with same letters indicated that there was no difference among groups, while with different letters indicated there was significant difference among groups.

economically efficient way to enhance the utilization of phytate phosphorus in nonruminant animal diets [10,24]. Some studies presented that plant phytase had obvious efficacies and could reduce the excrement of phosphorus and improve the utilization of phosphorus and/or calcium in broiler chicks, brown roosters, growing pigs $[16,25,26]$. Furthermore, it was reported that lowphosphorus diets were more beneficial for increasing phytase activity and enhancing the utilization of phosphorus $[15,27,28]$.

The present study used a common daily diet with adequate phosphorus and low-phosphorus diets to evaluate the utilization of calcium and phosphorus in PTC. The results showed that the effect of phytase supplementation in corn was quite pronounced. The apparent digestibility of calcium and phosphorus were significantly higher in PTC groups with phytase activity 500 FTU and above than that in PTC0 group, which was a low-phosphorus diets without phytase. In addition, the efficiency of phytase in PTC groups was similar as that from common diet and microbe. The result in our study was accordance with previous studies $[13,16,25,26]$.

In the present study, the apparent digestibility of phosphorus and calcium in growing pigs feeding with different level of phytase activity did not increased in a dose-dependent manner, which was in accordance with Zhang et al.'s study [29]. While Torrallardona et al.'s study [15] observed the improved apparent total tract digestibility of phosphorus in growing pigs and reduced phosphorus excretion in feces in a dose-dependent manner. One of the reasons could be explained by the different source of phytase. The microbial phytase used in Torrallardona et al.'s study [15] was supplemented directly into the diet and could be released completely to digest phosphorus, while these used in our's and Zhang's study [29] were expressed in genetically modified corns. In addition, the content of inorganic phosphorus in the low phosphorus diet in this study was just reduced by a third. Calcium and phosphorus could be completely released by the $500 \mathrm{KTU} / \mathrm{kg}$ phytase and could absolutely meet animal's nutritional requirement. Most of the phytase were expressed in the endosperm of maize [10], which led to the excess phytase stay in this layer and then could not be released when it was unnecessary.

\section{Conclusion}

Based on these results, it was concluded that except phytate phosphorus concentrations, the nutritional compositions of PTC had substantial equivalence to that of control corn. The efficacy of Aspergillus Niger-derived phytase expressed in transgenic modified corn was comparable to that expressed in microbe. In addition, the apparent digestibility of phosphorus and calcium in diet with PTC was enhanced obviously in pigs. As a consequence, PTC added to monogastric animal diets might be an economically efficient way to reduce the excrement of inorganic phosphorus and then decrease environment pollutions.

\section{Declaration}

Credit authorship statement: Conceptualization: X.Y and L.Y; Methodology: M.L and L.L; Experiments: L.L, D.M; Data Curation: L.L and J.W; Writing-Original Draft Preparation: L.L and J.W; Writing-Review \& Editing: L.Y; Supervision: X.Y and L.Y; Project Administration: L.Y and X.Y.

Acknowledgements: The authors wish to thank Ministry of Agriculture of China for their financial support of the project (2016ZX08011 - 005). The authors would also like to thank Beijing Origin for corn samples provided and Hongfu Zhang and his team for cannulation surgery.

\section{References}

1. Frost TJ, Roland DA Sr. The influence of various calcium and phosphorus concentrations on tibia strength and eggshell quality of pullets during peak production. Poult. Sci. 1991; 70: 963-969.

2. Sell PH, Ravindran V, Caldwell A, Bryden WL. Phytate and phytase: consequences for protein utilization. Nutr Rev. 2000; 13: 255-278.

3. Maenz DD. Enzymatic characteristics of phytases as they relate to their use in animal feeds in Enzymes in Farm Animal Nutrition. MR Bedford and GG Partridge, ed. CAB International, Wallingford, UK. 2001; 61-83.

4. Tahir M, Shim MY, Ward NE, Smith C, Foster E, Guney AC, et al. Phytate and other nutrient components of feed ingredients for poultry. Poult Sci. 2012; 91: $928-935$

5. Peeler HT. Biological availability of nutrients in feeds: Availability of major mineral ions. J. Anim. Sci. 1972; 35: 695-712.

6. Humer E, Schwarz C, Schedle K. Phytate in pig and poultry nutrition. J Anim Physiol Anim Nutr (Berl). 2015; 99: 605-625.

7. Sands JS, Ragland D, Baxter C, Joern BC, Sauber TE, Adeola O. Phosphorus bioavailability, growth performance, and nutrient balance in pigs fed high available phosphorus corn and phytase. J. Anim. Sci. 2001; 79: 2134-2142.

8. Johnston SL, Williams SB, Southern LL, Bidner TD, Bunting LD, Matthews $\mathrm{JO}$, et al. Effect of phytase addition and dietary calcium and phosphorus levels on plasma metabolites and ileal and total-tract nutrient digestibility in pigs. J. Anim. Sci. 2004; 82: 705-714.

9. Ravindran VP, Morel CH, Patridge GG, Hruby M, Sands JS. Influence of an Escherichia coli-derived phytase on nutrient utilization in broiler starters fed diets containing varying concentrations of phytic acid. Poult. Sci. 2006; 85: 82-89.

10. Chen R, Xue G, Chen P, Yao B, Yang W, Ma Q, et al. Transgenic maize plants expressing a fungal phyase gene. Transgenic Res. 2008; 17: 633-643.

11. McNaughton J, Roberts M, Smith B, Rice D, Hinds M, Rood T, et al. Comparison of broiler performance and carcass yields when fed diets containing transgenic maize grains from event DP- $\varnothing 9814 \varnothing-6$ (Optimum GAT), near-isogenic control maize grain, or commercial reference maize grains. Poult. Sci. 2008; 87: 2562-2572.

12. Bertoni G, Marsan PA. Safety risks for animals fed genetic modified (GM) plants. Vet. Res. Commun. 2005; 29: 13-18.

13. Gao CQ, Ma QG, Ji C, Luo XG, Tang HF, Wei YM. Evaluation of the compositional and nutritional values of phytase transgenic corn to conventional corn in roosters. Poult Sci. 2012; 91: 1142-1148. 
14. Lu L, Guo J, Li S, Li A, Zhang L, Liu Z, Luo X. Influence transgenic corn on the intestinal microflora and the fate of transgenic DNA and protein in digesta and tissues of broilers. PLoS One. 2015; 10: e0143408.

15. Torrallardona $\mathrm{D}$, Salvado R, Broz J. The supplementation of low-P diets with microbial 6-phytase expressed in Aspergillus oryzae increases $\mathrm{P}$ and $\mathrm{Ca}$ digestibility in growing pigs. J Anim Sci. 2012; 90: 77-79.

16. Casas GA, Stein HH. Effects of microbial phytase on the apparent and standardized total tract digestibility of phosphorus in rice coproducts fed to growing pigs. J Anim Sci, 2015; 93: 3441-3448.

17. Feng ST. The experimental minipigs in China, China Agriculture Press, Beijing, China. 2011.

18. Ge KY. An Overview of Nutrition Sciences. People's Medical Publishing House, Beijing, China. 2004.

19. Han JH, Yan YX, Men JH, Bian LH, Guo J. Comparison of ileal digested production of parental rice and rice genetically modified with cowpeas trypsin inhibitor. Biomed. Environ. Sci. 2006; 19: 42-46.

20. World Health Organization. Application of the principles of substantial equivalence to the safety evaluation of foods or food components from plants derived by modern biotechnology: report of a WHO workshop. Geneva; World Health Organization. 1995; 80.

21. Mei XH, Xu WT, He XY, Cao SS, Li XH, Liu Q, et al. Research progress in countermeasures of food safety assessment to new type of genetically modified plants. Food Science. 2013; 5: 308-312.

22. Leytem AB, Widyaratne GP, Thacker PA. Phosphorus utilization and characterization of ileal digesta and excreta from broiler chickens fed diets varying in cereal grain, phosphorus level, and phytase addition. Poult. Sci. 2008; 87: 2466-2476
23. Augspurger NR, Spencer JD, Webel DM, Wolter BF, Torrance TS. An Escherichia coli-derived phytase can fully replace inorganic phosphorus in maize-soybean meal diets for growing-finishing pigs. Anim. Feed Sci. Technol. 2009; 154: 254-259.

24. Nyannor EKD, Adeola O. Corn expressing an Esch-erichia coli-derived phytasegene: comparative evaluation study in broiler chicks. Poult. Sci. 2008; 87: 2015-2022.

25. Nyannor EKD, Bedford MR, Adeola O. Corn expressing an Escherichia coliderived phytase gene: residual phytase activity and microstructure of digesta in broiler chicks. Poult. Sci. 2009; 88: 1413-1420.

26. Gonzalez-Vega JC, Walk CL, Stein HH. Effect of phytate, microbial phytase, fiber, and soybean oil on calculated values for apparent and standardized total tract digestibility of calcium and apparent total tract digestibility of phosphorus in fish meal fed to growing pigs. J Anim Sci. 2015; 93: 4808-4818.

27. Yu M, Bian LQ, Cheng Bo. Effect of phytase supplementation in diet on growth performance and the apparent digestibility of phosphorus, calcium and protein in nursery pigs fed diets. Husbandry and veterinary. 2013; 2 : 32-36.

28. Wang ZH, Yang WR, Guo BL, Wang DH, Liu XM, Zhang CY, et al. Effect of phytase supplementation on growth performance, serum biochemical parameters and apparent digestibility of nutrient in nursery pigs fed diets with different level of inorganic phosphorus. Acta Veterinaria et Zootechinica Sinica. 2015; 46: 1891-1898.

29. Zhang J. Effect of trans-phytase-gene corn on growth performance, nutrient utilization and related biochemical indexes of pig. Hebei Agricultural University, Shijiazhuang. 2012. 